Patent law

\section{Boost for Canadian drug research}

Washington

AFTER a long and painful gestation, the Canadian government has finally given birth to proposals for changes in patent law. The amendments, actively sought by the pharmaceutical industry, will restore to patent holders exclusive rights to sales of patented drugs. In exchange, the government will require pharmaceutical companies to double their current research commitments in Canada.

Since 1969, Canada has had a unique law that allows generic drug manufacturers to obtain licences to produce patented drugs at any time. Once approved for sale by the health protection branch of the Department of Health and Welfare, generic manufacturers are in most cases obliged only to pay a 4 per cent royalty to the patent holder. Major, multi-national drug companies argue that this "compulsory licence" system discourages domestic investment and cuts sharply into profits. But for consumers, the benefits are obvious. A government report last year estimated that Canadians are saving $\$ 220 \mathrm{mil}$ lion a year in drug costs under this arrangement.

Knowing that changing the compulsory licence system will provide political hay for the opposition, the government has several times delayed introduction of the amendments. But as the government has a 70 -seat majority, the bill should pass into law unscathed. The government hopes to deflect some consumer criticism by establishing a new Drug Prices Review Board that can remove the protection from compulsory licences for companies whose prices rise too high.

Under the new laws, which will be presented to parliament in the fall but will apply from 27 June this year, companies will not be subject to compulsory licences for ten years. An additional ten years' protection from compulsory licences is offered to companies that manufacture a new drug in Canada. In exchange for such protection, the government has set targets for research expenditure by drug companies. Companies must increase research and development outlay to 8 per cent of sales by 1990 , and 10 per cent by 1995 . Research expenditure is now running at 5 per cent. Failure to comply with these targets could mean loss of protection from compulsory licences.

Other changes will bring Canada's patent laws in line with practices in most industrialized countries. Following the European model, patent applications will be open to public inspection 18 months after submission. Canada also plans to move away from the US system of awarding patents on a "first to invent" basis in favour of the European "first to file" ap- proach. The government will also change patent terms from 17 to 20 years, and ratify the patent cooperation treaty.

While pharmaceutical industry trade groups have not yet formally endorsed the proposals, at least one pharmaceutical company is enthusiastic about them. Merck \& Co. is moving immediately to complete plans for a $\mathrm{Cdn} \$ 20$ million addition to its research complex in Montreal and expects to begin construction next year. By 1990, Merck estimates it will spend an additional $\$ 100$ million on research and development as well as creating 50 new scientific posts in Canada.

\section{Tokyo} was the US Challenger, then Europe's Ariane, now Japan's shuttle has crashed to Earth seconds into its maiden flight. The craft's loss, however, is not a major setback - the shuttle was only a twometre plastic model.

Last month, scientists from Japan's Institute of Space and Astronautical Sciences (ISAS), the space institute that earlier this year sent two probes to Halley's comet, test-flew a model of an orbital

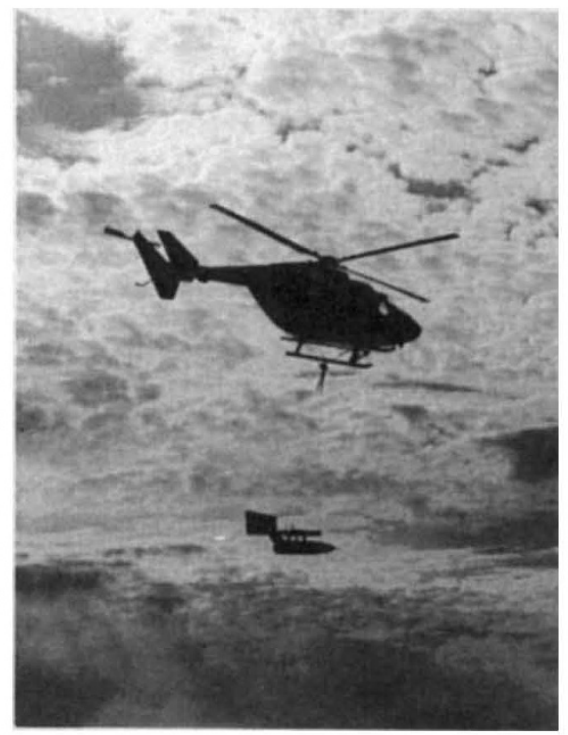

re-entry vehicle. The white twin-finned shuttle was released at $1,000 \mathrm{~m}$ from a helicopter flying at $200 \mathrm{~km}$ per h $5 \mathrm{~km}$ off the Akita coast of Japan.

Equipped with a three-axis accelerometer, an angular velocity meter, a geomagnetic attitude sensor, an air-pressure sensor and a microprocessor, the model was supposed to be controlled from the ground and to relay information on altitude, attitude and velocity. But no sooner
THIs is not the year for space flight. First it
While victories are being won in Canada, the pharmaceutical industry has not been so fortunate in its dealings with the United States. For years, US drug companies have been seeking a change in the law to allow them to manufacture and export drugs that are not approved for sale in the United States.

Earlier this year an industry-approved bill reached the floor of the Senate, and the House was poised to consider similar legislation. But at the last moment, opponents added amendments so unpalatable to the industry that it withdrew its support for the legislation. The amendments would have placed tighter controls on export of infant formulas, and required additional notification procedures for exports of certain drugs.

Joseph Palca

\title{
A short flight for Japan's shuttle
}

was the shuttle set free than it looped the loop, turned into dive and 35 seconds later plunged headlong into the sea.

A second test a few days later with a back-up model was more successful. After release, the shuttle remained airborne and glided steadily for $4.2 \mathrm{~km}$ while descending from 800 to $500 \mathrm{~m}$. But it then veered left, failed to respond to correction signals from the ground, and 48 seconds later dived into the sea.

The ISAS team nevertheless considers the experiments a partial success. The telemeter system performed flawlessly and relayed data to Earth which show that the on-board roll stabilizer and yaw damper struggled valiantly to keep the shuttle on a steady course. But with no more models and a limited annual budget of only 100 million yen $(£ 400,000)$, no further tests are planned this year.

The ISAS Working Group on Winged Vehicles, set up in 1982, is headed by Professor Makoto Nagatomo and has been carrying out computer simulation studies, wind tunnel tests and the present ballistics tests on Japan's shuttle of the future. Once a working model is made, the group hopes to attach a bigger version to a single-stage S-520 sounding rocket - but that would require an increase of two orders of magnitude in its budget, and funds are not yet forthcoming from the Ministry of Education, Science and Culture.

Beyond that, Nagatomo has outlined plans to develop a Highly Manoeuvrable Experimental Space (HIMES) Vehicle by incorporating a cryogenic engine into the shuttle. The HIMES vehicle could then be used as a self-contained re-usable sounding rocket or even as an orbital re-entry vehicle. But ISAS has no ambitions to build a manned shuttle - that is the preserve of the National Aerospace Laboratory and the National Space Development Agency.

David Swinbanks 